\title{
Intranet Automation of Human Resource Management System
}

\author{
Anand Kotasthane ${ }^{1}$, Akshay Bahade ${ }^{2}$, Kaustubh Chinchalkar ${ }^{3}$, Prasad \\ Gawande $^{4}$, Ms. P K Karmore ${ }^{5}$ \\ ${ }^{1}$ Student, Computer Science Department, Dr. Babasaheb Ambedkar College of Engineering, Nagpur \\ ${ }^{2}$ Student, Computer Science Department, Dr. Babasaheb Ambedkar College of Engineering, Nagpur \\ ${ }^{3}$ Student, Computer Science Department, Dr. Babasaheb Ambedkar College of Engineering, Nagpur \\ ${ }^{4}$ Student, Computer Science Department, Dr. Babasaheb Ambedkar College of Engineering, Nagpur \\ ${ }^{5}$ Head of Department, Computer Science Department, Dr. Babasaheb Ambedkar College of Engineering, \\ Nagpur
}

\begin{abstract}
The main aim of the project is to develop a Human Resource Module for the Intranet Automation of HR Software for an organization. The module enhances good communication facilities between employees and $H R$ Administrator. To allow the HR of an organization to update the employee details whenever there is a change in the employee profile pertaining to that organization. The objective of the project is to create a tool for $H R$ department which helps it in giving confirmation to a recruited employee. HR department will have a CV and record of an employee's Interview in its database. Confirmation will be made on the basis of this data and a process known as SWOT.
\end{abstract}

Keywords - ASP.NET, HRMS, intranet, SQL, SWOT analysis.

\section{INTRODUCTION}

The revolutionary trends of computerization have reached the peaks achieving global goals in all fields and sectors. The HRMS systems getting computerized are leading to a new and innovative way to approach to above said. With the major organizations hosting services of HRMS our project specifically aims to the total computerization of the HRMS. With the total automation of HRMS, the manual dependency is minimized to a large extent. It inherits all the properties of computerizing a system which includes quick response, less processing time, fast recovery, robustness, flexibility, reliability, scalability. Today's trend demands high rate of automation for the HRMS as the organizations are growing in exponential form and maintaining employee records in a consistent format. To satisfy the needs of clients, today's organization need more and more of workforce. The HRMS system takes care of this by taking in resumes from new aspirants and allowing the HR to view them in and do selections there upon.

The main modules of the project are:

1. Database Design

2. Selection Process:-

$\circ$ Interview

- Confirmation

\section{LITERATURE REVIEW}

HR executives rely on internal or external IT professionals to develop and maintain an integrated HRMS. Before the client-server architecture evolved in the late 1980s, many HR automation processes were relegated to mainframe computers that could handle large amounts of data transactions. In consequence of the high capital investment necessary to buy or program proprietary software, these internally developed HRMS were limited to organizations that possessed a large amount of capital. The advent of client-server, application service provider, and software as a service or human resource management systems enabled increasingly higher administrative control of such systems. The project works on intranet network.

Human Resource Management Software has implemented different modules such as Library, Project Management, Marketing, etc. These modules are helpful in connecting all the employees working in the organization in those respective departments. But there are a few shortcomings of above modules which do not allow full automation of HRMS.

The system has not implemented the HR Module for the employees regarding his/her

General details - Personal information

Skills Details - Technical aspects

Project analysis - Technical Experience 
Decision in assigning proper skillful hands for the project is an important issue in HR Module. The HR Administrator should report with the personal holding the necessary skills required for the project assignment. The decision in making analysis about the employee's skills is of prime importance.

The proposed system provides detail general information about the employee along with Educational, Certification, Skill and Project details. It enhances the HR Management in adding, viewing and updating employees' details and generates various reports regarding employee's skill and experience. Users of SWOT analysis need to ask and answer questions that generate meaningful information for each category (strengths, weaknesses, opportunities, and threats) to make the analysis useful and find their competitive advantage.

\section{SWOT ANALYSIS}

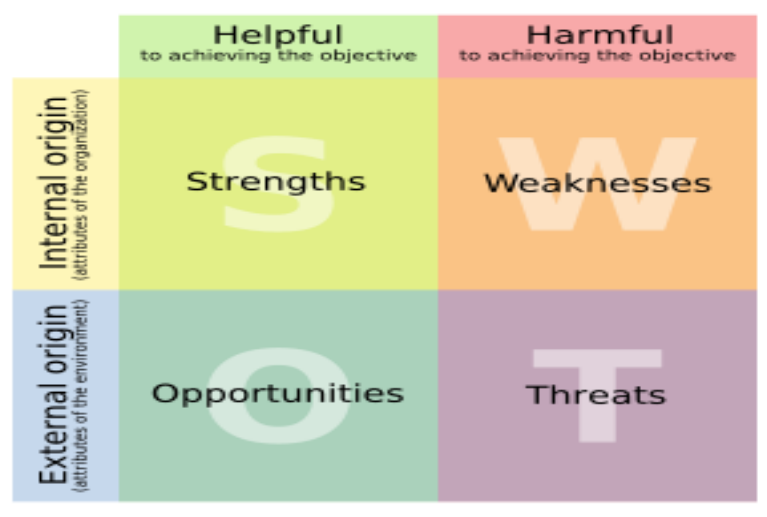

Fig. SWOT Analysis

The SWOT analysis is a structured planning method used to evaluate the Strengths, Weaknesses, Opportunities, and Threats involved in a project or in a business venture. A SWOT analysis can be carried out for a product, place, industry or person. It involves specifying the objective of the business venture or project and identifying the internal and external factors that are favorable and unfavorable to achieving that objective.

Setting the objective should be done after the SWOT analysis has been performed. This would allow achievable goals or objectives to be set for the organization.

- Strengths: characteristics of the business or project that give it an advantage over others.

- Weaknesses: are characteristics that place the team at a disadvantage relative to others

- Opportunities: elements that the project could exploit to its advantage

- Threats: elements in the environment that could cause trouble for the business or project

Identification of SWOTs is important because they can inform later steps in planning to achieve the objective. First, the decision makers should consider whether the objective is attainable, given the SWOTs. If the objective is not attainable a different objective must be selected and the process repeated .Users of SWOT analysis need to ask and answer questions that generate meaningful information for each category (strengths, weaknesses, opportunities, and threats) to make the analysis useful and find their competitive advantage.

\section{DISCUSSION}

The evaluation of the HRM department is based on three driving forces. The following three forces must be addressed by HRM departments that want to continuously increase their value while reducing costs. 1. Information technology; HRM professionals are facing a digital future. The rapid growth in the field of computer hardware, software, networking, and telephony services is absolutely essential to the HRM movement. 2. High-speed management; to be competitive, all companies must work smarter and faster. Intranet HRM is definitely a smarter and quicker form of service delivery than traditional HRM.

3. Networked organizations; Intranet HRM departments are more likely to emerge in networked organizations than in traditional and bureaucratic companies. The proliferation of information technology such as local area networks, e-mail, and corporate intranets are the trademarks of a flatter networked company.

All of these forces reflect the enormous impact that information technology has, and will continue to have, on every process and procedure in the HRM department. Successful information of a intranet HRM department will clearly increase a company competitive advantage. 


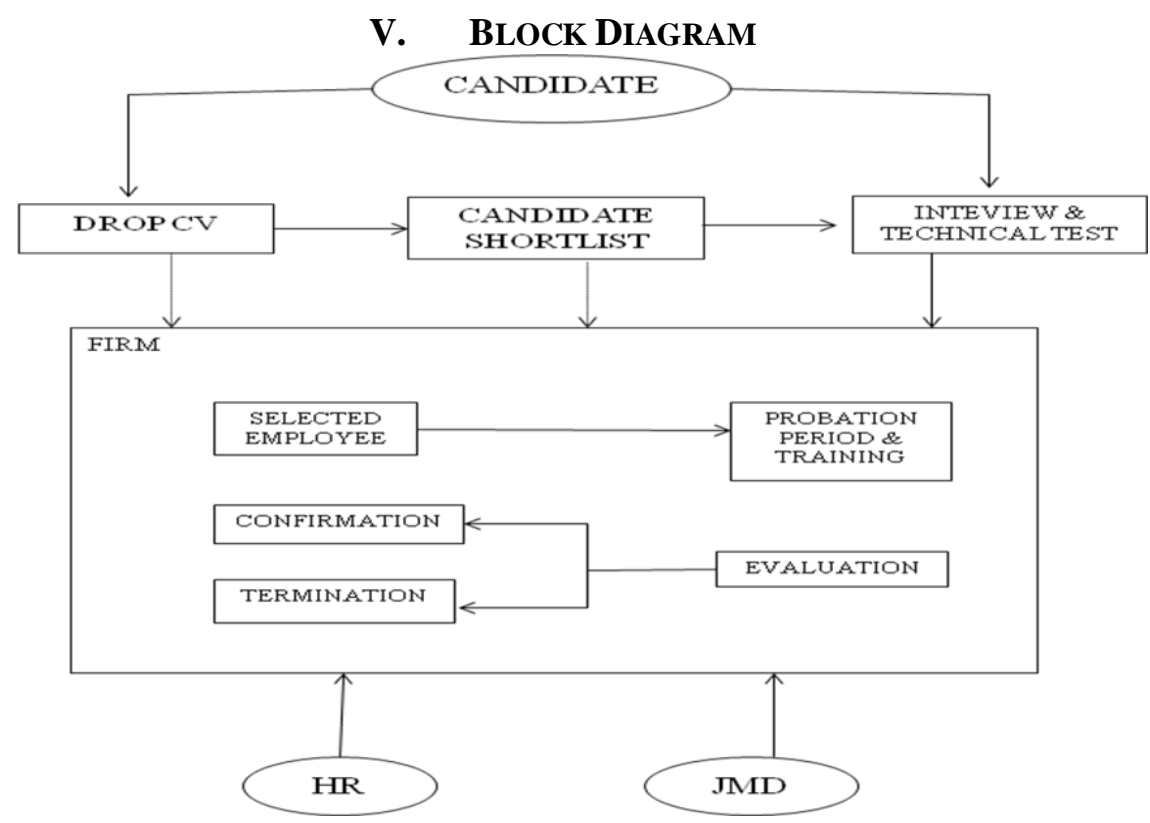

Fig. Block diagram of HRMS

\section{Implementation}

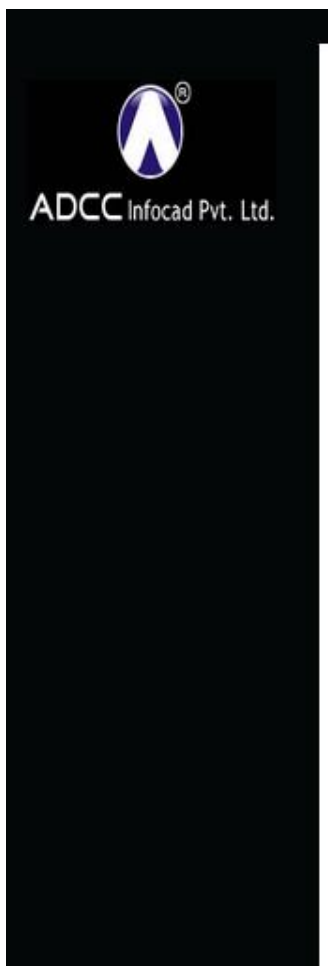

Welcome to ADCC

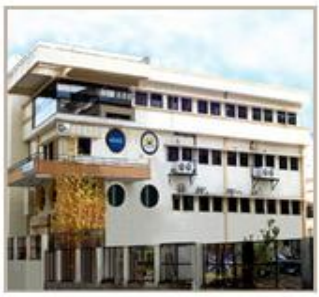

ADCC Infocad Pvt Ltd is an ISO 9001:2008 certified, NSIC-CRISIL Rated \& NASSCOM Registered Company and part of Meghe Group of Institutions.

Meghe group is a conglomerate, which has varied interests in the fields of Basic and Professional Education, Training, Hospitals, Industries \& Estates, Banking, Information Technology, Media \& Entertainment etc. based out of Nagpur for last three decades. $\mathrm{ADCC}$ Infocad Pvt. Ltd is a central India based Engineering and IT services company providing "Total Solution" in Engineering Services, Geographical Information System, Management Information System, CAD conversion, Geo-spatial Solutions and Utility Application Software development services to clients in India and abroad belonging to Meghe Group. LOGIN

User ID:-

Password:-

Bign_IN Bign_UP

Fig. Login Page 


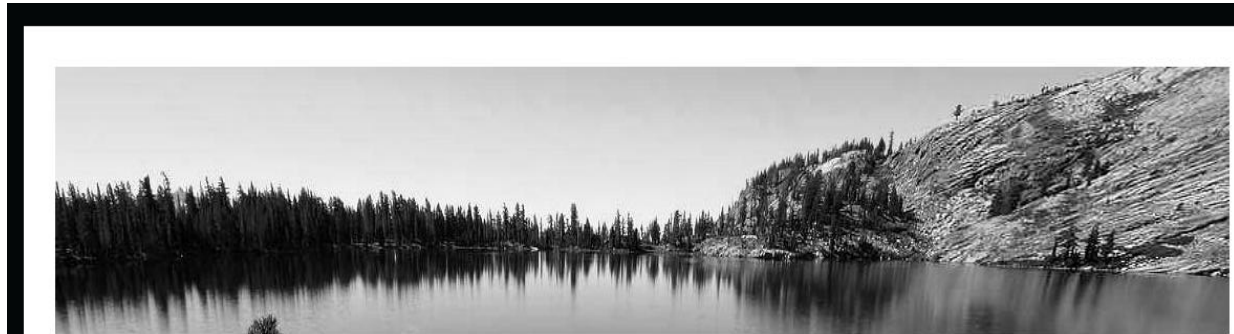

= EMPLOYEE INFORMATION

NEW

UPDATE

CV

a TOOLS

CALCULATOR

NOTEPAD

WORDPAD

\begin{tabular}{|l|l|l|l|l|l|l}
\hline Select & Emp_id & Emp_Name & DOJ & Manager_name & Departement & Edit \\
\hline 0 & 1 & kumar & $30 / 9 / 2013$ & pree & net & Seler \\
\hline & & & & & & Seler \\
\hline & 2 & pree & $30 / 9 / 2013$ & nikhil & net & \\
\hline
\end{tabular}

Fig. Admin's Home Page

\begin{tabular}{|c|c|}
\hline & ADCC CV-Form \\
\hline Application for post of & 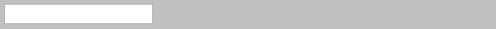 \\
\hline $\begin{array}{l}\text { Mode of } \\
\text { application/Reference }\end{array}$ & \\
\hline Date of Application & - \\
\hline Name of Candidate & $\mathrm{a}$ \\
\hline Contact Details & \\
\hline Mb. No : & 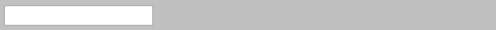 \\
\hline Email-Id & 口 \\
\hline HomeTown & L \\
\hline $\begin{array}{l}\text { Total Years of } \\
\text { Experience }\end{array}$ & \\
\hline Current Employer & $\square$ \\
\hline Qualification & \\
\hline College & \\
\hline Year of Passing & \\
\hline
\end{tabular}

Fig. CV Form

\begin{tabular}{|c|c|c|c|c|c|}
\hline \multicolumn{6}{|c|}{ Performance And Approach Review By SWOT Analysis } \\
\hline Employee Name : & 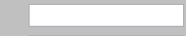 & Date : & & 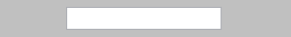 & \\
\hline Department: & & Evaluators Name & & & \\
\hline & STRENGTH & WEAKNESS & & & \\
\hline Domain Knowledge & & & & \multicolumn{2}{|l|}{ Lack Of Knowledge } \\
\hline Capability-Task Execution & - & $x_{2}$ & 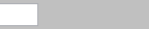 & \multicolumn{2}{|l|}{ Low Morale / Commitment } \\
\hline Attitude / Behaviour & & & & \multicolumn{2}{|l|}{ Distraction If Any } \\
\hline & OPPORTUNITY & THREATS & & \multirow{2}{*}{\multicolumn{2}{|c|}{ Lack of Learning Capabilities }} \\
\hline Competative Preparedness & & & & & \\
\hline Leadership Quality & & - & & \multicolumn{2}{|l|}{ Severe Behaviour Problems } \\
\hline Dynamic / Multitasking & & & & \multicolumn{2}{|l|}{ Indiscipline } \\
\hline & Rating:(On Scale 1 To 10) & (1 To $3=$ POOR & 4 To $5=$ AVERAGE & 6 To $7=$ GOOD 8 To $9=$ VERY GOOD & $10=$ EXCELLENT) \\
\hline
\end{tabular}

Fig. SWOT Analysis Form 


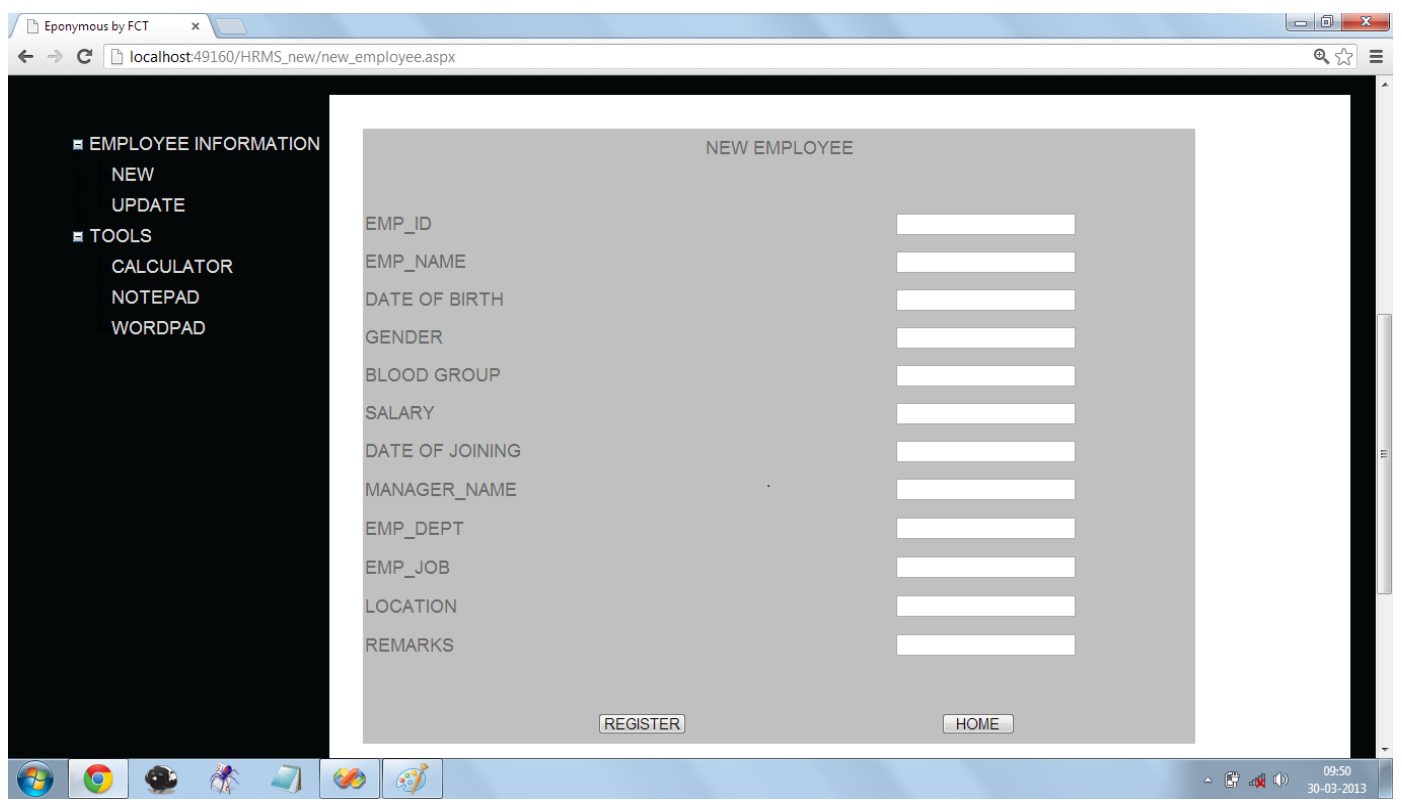

Fig. New Employee Form

\section{Conclusion}

HRMS is a tool to automate and support HR processes. HRMS (Human Resource Management System) is advance business solution which provides a complete support in the management of all processes, activities, data and information required to manage human resources in a modern company. It is an efficient, reliable, easy to use tool, accessible to a broad group of different users.

HRM is a way of implementing HR strategies, policies, and practices in organizations through a conscious and directed support of web-technology-based channels. It covers all aspects of human resource management like personnel administration, education and training, career development, job descriptions, hiring process, employee's personal pages, and annual interviews with employees. Therefore intranet based HRMS is the way to manage human resources.

The applications of the paper are:

a. Can be efficiently used in corporate sector like Bank, IT firm, etc and also in educational institutes. This software can be utilized for particular tasks like pronunciation teaching for several languages. It can also be utilized with interactive educational applications.

b. $\quad$ Can be used in public sector.

Online Interview is our distinct feature from rest existing websites of companies.

\section{Journal Papers:}

\section{REFERENCES}

[1] B. Naga Jyothi, G.R. Babu and I.V. Murali Krishna, "Object Oriented and Multi-Scale Image Analysis: Strengths, Weaknesses, Opportunities and Threats-A Review", Journal of Computer Science 4 (9): 706-712, 2008.

[2] Sean A. Way, James W. Thacker, "The successful implementation of strategic human resource management practices: A Canadian survey", Published in the International Journal of Management, 2001, V-18, pp 25-32.

\section{Books:}

[1] "Let Us C\#”, By Yashwant Kanetkar and Asang Dani, BPB Publications, New Delhi, India.

[2] "SQL Server Express - A Complete Reference Guide", By Pinal Dave. 